\title{
The Cluster-Randomized BRIGHT Trial: Proactive Case Finding for Community-Dwelling Older Adults
}

Ngaire Kerse, $M B C b B, P b D^{1}$

Chris Mclean, DipMngmt ${ }^{1,2}$

Simon A. Moyes, MSc ${ }^{1}$

Katby Peri, RN, $\mathrm{PbD}^{3}$

Terence $\mathrm{Ng}, \mathrm{MSc}^{1}$

Laura Wilkinson-Meyers, $P b D^{1}$

Paul Brown, $P b D^{1,4}$

Nancy Latham, PbD 5

Martin Connolly, MBBS, $M D^{6}$

'School of Population Health, Faculty of Medical and Health Sciences, University of Auckland, Auckland, New Zealand

${ }^{2}$ Interdisciplinary Trauma Research Centre, AUT University, Auckland, New Zealand

${ }^{3}$ School of Nursing, Faculty of Medical and Health Sciences, University of Auckland, Auckland, New Zealand

${ }^{4}$ Health Sciences Research Institute, University of California, Merced, California

${ }^{5}$ Health and Disability Research Institute, Boston University, Boston, Massachusetts

${ }^{6}$ Freemason's Department of Geriatric Medicine, Faculty of Medical and Health Sciences, University of Auckland, Auckland, New Zealand

Conflicts of interest: None of the authors bave financial relationships with any organizations that might bave an interest in the submitted work in the previous 3 years, and none bave other relationships or activities that could appear to bave influenced the submitted work.

\section{CORRESPONDING AUTHOR}

Ngaire Kerse, MBChB, $\mathrm{PhD}$

School of Population Health,

Tamaki Campus

University of Auckland

Private Bag 92019

Auckland, New Zealand

n.kerse@auckland.ac.nz

\begin{abstract}
PURPOSE People are now living longer, but disability may affect the quality of those additional years of life. We undertook a trial to assess whether case finding reduces disability among older primary care patients.
\end{abstract}

METHODS We conducted a cluster-randomized trial of the Brief Risk Identification Geriatric Health Tool (BRIGHT) among 60 primary care practices in New Zealand, assigning them to an intervention or control group. Intervention practices sent a BRIGHT screening tool to older adults every birthday; those with a score of 3 or higher were referred to regional geriatric services for assessment and, if needed, service provision. Control practices provided usual care. Main outcomes, assessed in blinded fashion, were residential care placement and hospitalization, and secondary outcomes were disability, assessed with Nottingham Extended Activities of Daily Living Scale (NEADL), and quality of life, assessed with the World Health Organization Quality of Life scale, abbreviated version (WHOQOL-BREF).

RESULTS All 8,308 community-dwelling patients aged 75 years and older were approached; 3,893 (47\%) participated, of whom 3,010 (77\%) completed the trial. Their mean age was 80.3 (SD 4.5) years, and 55\% were women. Overall, $88 \%$ of the intervention group returned a BRIGHT tool; 549 patients were referred. After 36 months, patients in the intervention group were more likely than those in the control group to have been placed in residential care: $8.4 \%$ vs $6.2 \%$ (hazard ratio $=1.32 ; 95 \% \mathrm{Cl}, 1.04-1.68 ; P=.02$ ). Intervention patients had smaller declines in mean scores for physical health-related quality of life (1.6 vs 2.9 points, $P=.007$ ) and psychological health-related quality of life (1.1 vs 2.4 points, $P=.005)$. Hospitalization, disability, and use of services did not differ between groups, however.

CONCLUSIONS Our case-finding strategy was effective in increasing identification of older adults with disability, but there was little evidence of improved outcomes. Further research could trial stronger primary care integration strategies.

Ann Fam Med 2014;12:514-524. doi: 10.1370/afm.1696.

\section{INTRODUCTION}

$\Lambda$ $\mathrm{s}$ the proportion of older adults in the population rises, the increasing burden of disability challenges health systems. Ways of increasing disability-free life tantalize researchers and health planners alike. Intensive geriatric assessment and management are effective in community settings ${ }^{1}$; however, the exact application and success of preventive interventions differ depending on the health system, ${ }^{2}$ and failures, such as increased placement in residential care as a result of case management, ${ }^{3,4}$ challenge decisions to widely implement preventive visits for older adults. The most effective way to intervene is not known.

After using preventive visits for 10 years, the United Kingdom concluded that there was no impact of systematic assessment. ${ }^{5,6}$ Germany, Italy, France, the Netherlands, Australia, and Denmark ${ }^{7}$ continue to offer publicly funded proactive assessment for older adults. In the United States, managed care organizations offer geriatric assessment to improve out- 
comes, ${ }^{8}$ and there are growing moves toward systematically identifying particular groups with high levels of health care use for additional attention. ${ }^{9}$

We undertook a trial in New Zealand to clarify the effectiveness of a first step in the proactive process: population-level screening to identify unaddressed disability in the context of organized primary health care. New Zealand has publicly available community geriatric and support services, similar to those available in managed care in the United States and in public insurance-

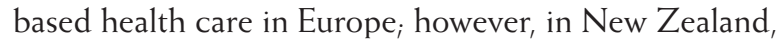
entry to the geriatric care system is not systematized.

New Zealand has an integrated primary health care system whereby $98 \%$ of all older adults are enrolled with a general practice; the system is supported by publicly funded community services and geriatrics specialist multidisciplinary teams coordinated from secondary care. Aging-related residential care is available after standardized assessment and is publicly subsidized on a means-tested basis. Practice-based quality improvement processes are common and accepted in general practices, meaning practice-based interventions are feasible.

To identify older adults with disability and prevent its progression, we developed a 2 -step case-finding process, similar to that of other trials..$^{10,11}$ The first step of the process consisted of a validated self-completed questionnaire, the Brief Risk Identification Geriatric Health Tool (BRIGHT). ${ }^{12}$ This trial aimed to assess the impact of using this first step to improve case finding on hospitalizations, residential care placement, functional decline, and quality of life for community-dwelling older adults.

\section{METHODS}

We used a pragmatic cluster-randomized trial to test the hypothesis that case finding using the BRIGHT tool would improve disability-related outcomes. As primary care was the preferred setting for intervention, a cluster design was necessary to avoid contamination. ${ }^{13}$

\section{Participants and Recruitment}

Detailed eligibility criteria are reported elsewhere. ${ }^{14}$ All community-dwelling patients of participating primary care practices aged 75 years and older were eligible. Those living in residential care or receiving palliative care and those who were terminally ill were not eligible.

All primary care practices in 3 regions were approached personally in random order. Patient participants were recruited by invitation letter from the primary care physician sent to all eligible patients. We performed telephone follow-up with all nonrespondents. The New Zealand Multiregional Ethics Committee approved the trial, and written informed consent was obtained.

\section{Measures}

Trained telephone interviewers conducted interviews, and trained nurses interviewed patients at home if the they were unable to communicate by telephone. Interrater reliability was assessed by dual interviews. At baseline, patients' age, sex, marital status, living arrangement, and educational level were established by self-report, as were patient and spouse occupations. Health status was estimated from total number of medications used per day, hospitalizations in the last year, and presence of diagnoses from a menu list. Smoking status was ascertained as pack-year history, and falls in the past year by recall. Cognition was assessed using the abbreviated mental test score (AMTS). ${ }^{15}$ At baseline and at 18 months and 36 months of follow-up, we assessed depression with the 15 -item Geriatric Depression $\mathrm{Scale}^{16}$; receipt of home help services, home help, and personal care; and satisfaction with primary care using 3 questions pertaining to patients' last consultation: care and concern, involvement in decision making about care, and time spent with the primary care physician.

\section{Outcomes}

The trial's primary outcomes were residential care placement and hospitalizations ascertained from institutional and primary care records matching the National Health Identification number. At the end of the trial, we assessed both hospitalizations overall and ambulatory care-sensitive hospitalizations (thought to be sensitive to primary care intervention), classified by standard Ministry of Health procedures. ${ }^{17,18}$

For secondary outcomes, disability was assessed with the Nottingham Extended Activities of Daily Living Scale ${ }^{19}$ (NEADL); possible scores range from 0 to 22 , with a low score indicating more assistance in daily tasks and a high score indicating more independence. We assessed functional ability from 2 domains-Basic Mobility (MCID 4.2) and Daily Activity (activities of daily living and instrumental activities of daily living, MCID 3.7) of the Activity Measure for Post-Acute Care (AM-PAC) scale; for these domains, a low score indicates worse function. ${ }^{20}$ Quality of life was assessed with the World Health Organization Quality of Life scale, abbreviated version (WHOQOL-BREF), ${ }^{21,22} \mathrm{a}$ sensitive measure thought to be more responsive to change than the 12-item Short Form Healthy Survey; a higher score indicates better quality of life, and a change of 3 to 5 points is considered clinically relevant. The AMTS, NEADL, and WHOQOL-BREF were validated for telephone use. ${ }^{23}$

We also assessed physical function in a subgroup of patients having a greater level of disability. If the answer to either of 2 questions on the NEADL, "Do 
you get in and out of the car?" and "Do you take hot drinks from one room to another?" was "no" or "I need help with this," the patient was asked to accept a home visit to establish physical function using the Short Physical Performance Battery ${ }^{24}$ and grip strength using a standard hand grip dynamometer.

During all baseline telephone interviews and home assessments, if the patient was found to be critically ill, the researchers contacted the usual physician. This procedure was used only twice.

\section{Randomization and Blinding}

After recruitment, clusters of participants and practices were block-randomized (by area) to an intervention group or control group by a distant statistician not involved in recruitment using a computer generated randomization schedule. Only the intervention trainer/ project manager (C.M.) knew the group allocation. All other research staff were blinded to practice and participant allocation until completion of the trial. Patients were informed that the trial was testing a practicebased strategy to promote healthy aging. Practices were not blinded, and geriatrics personnel receiving the referrals for BRIGHT participants from practices were partially blinded. The referrers were instructed not to mention the trial in the referral but did not always follow that instruction.

\section{Study Groups}

One researcher (C.M.) trained the practices in intervention processes. Every year for 3 years, patients in intervention practices were sent a birthday card from their general practitioner (the first step in our intervention) containing the BRIGHT questionnaire (Supplemental Appendix 1), an 11-item questionnaire asking about health and activities of daily living. If their score was less than 3, no further action was taken. A score of 3 or higher was the validated trigger level ${ }^{12}$ for the second step, a referral by the practice nurse to regional publicly funded geriatrics assessment and rehabilitation services. For the intervention period, practices were provided funding for 1 day per month of a practice nurse's salary to complete the BRIGHT recall process, and regional geriatrics services were bulk funded to provide additional assessment services to trial participants.

The control group received usual care, which included referrals to the geriatrics community team when considered necessary by the primary health care team.

The publicly funded assessment and rehabilitation services had several components: triage of referred patients, a multidisciplinary team (physiotherapist, occupational therapist, gerontology nurse, geriatrician, and social worker) to complete a comprehensive assessment ${ }^{25}$ if needed, then coordination of support services and/or rehabilitative services through direct funding, and geriatric medical expertise (part of the team) as required. Geriatrics teams gave feedback to primary care practices about health care and support services decisions, and primary care maintained responsibility for overall medical care of the participants. These services were available to both groups, but the intervention group was systematically screened and all eligible patients were referred.

\section{Sample Size}

To show that a reduction of $15 \%$ in the hospitalization rate of 61.7 per 100 to 52.4 per 100 was not due to chance alone, 622 patients per group were required, for a total of 1,244 patients. These patients were gathered in clusters from primary care practices. The average cluster size was estimated at 96 , assuming an $80 \%$ response rate (achieved in other trials by this team) and an $80 \%$ completion rate (also achieved in previous trials) for the average 3 -physician practice. Adjusting the sample size for an intraclass correlation coefficient of 0.0238 , based on hospitalization reported in the Medical Research Council trial, ${ }^{6}$ a design effect of 3.261 was estimated using the Donner equation. ${ }^{13}$ Inflating the sample size of 1,244 by 3.61 , we needed 4,057 patients from 42 practices.

\section{Analyses}

We compared main outcomes between the groups using mixed effects regression models. We computed both patient hospitalizations per year of the trial and the rate of hospitalizations per person-year for each group. Hospitalization was a binary dependent variable: a patient was or was not hospitalized during the 3 years of follow-up. Propensity to be hospitalized frequently was controlled for by putting number of hospitalizations in the year before the study in the model as a fixed effect covariate. Number of hospitalizations in the 3 years of follow-up was a Poisson dependent variable. Primary care practices nested within regions were added to the random effect component in these mixed effects models (those hospitalized and hospitalization rate) to adjust for clustering. We compared ambulatory care-sensitive hospitalizations using the same methods. Time from randomization to residential care placement was compared using Cox proportional hazards models.

For secondary outcomes, we analyzed the dependent variables of quality of life (WHOQOL-BREF scores), function (NEADL scores), and functional ability (AM-PAC scores) in separate generalized linear regression models with repeated measures adjusting for clustering by practice and region. Satisfaction with general practitioner care, use of emergency depart- 
ments, and use of geriatric services were compared using regression techniques. Intraclass correlation coefficients were calculated for hospitalization, residential care placement, quality of life, depression, and function.

\section{RESULTS}

\section{Participants}

All 8,308 community-dwelling participants aged 75 years or older in participating practices were approached (Figure 1). ${ }^{26}$ A total of 3,893 (46.8\%) participated, of

\section{Figure 1. Flow of patients through the BRIGHT trial and numbers triggering referral and referred.}

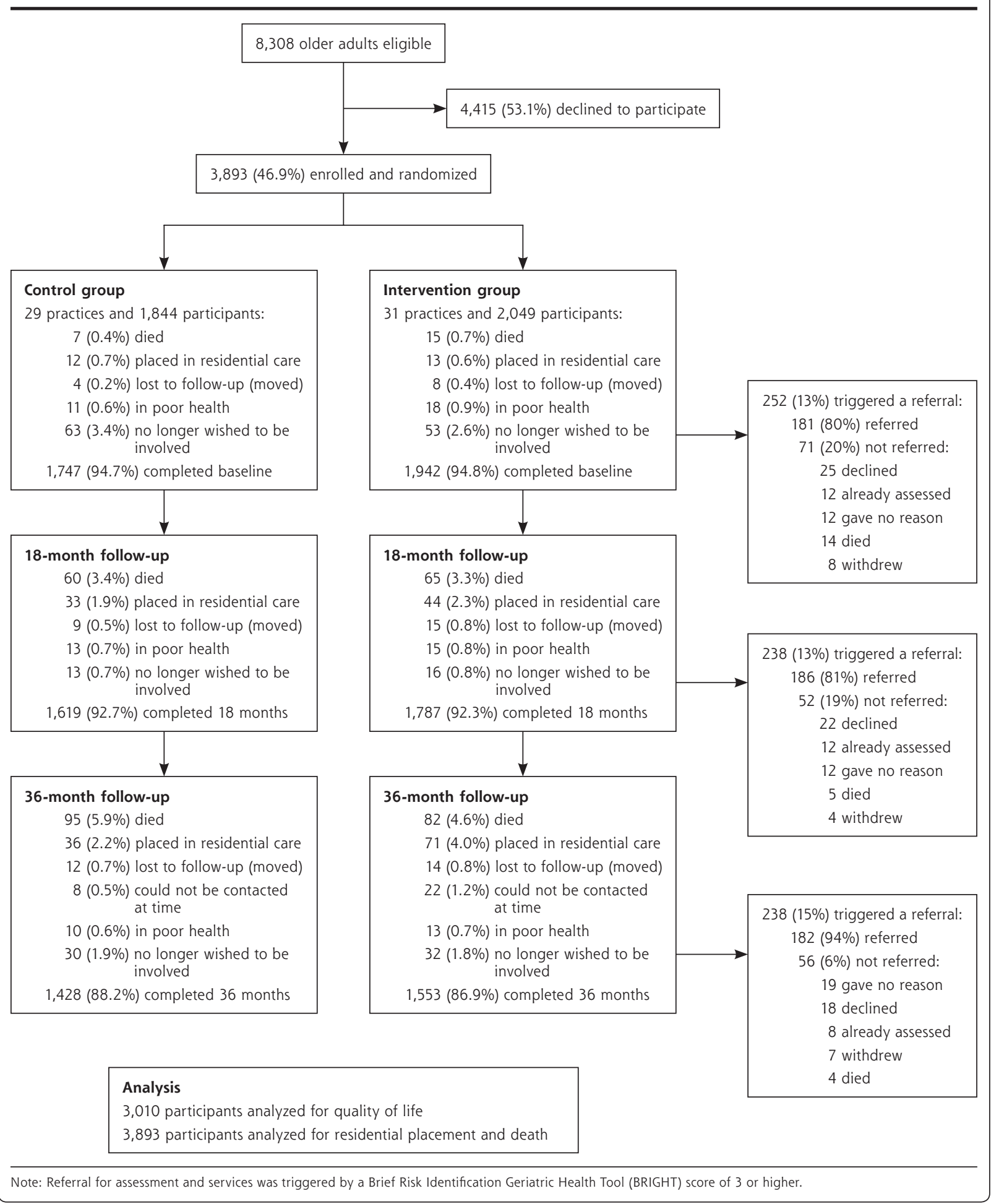


whom $77 \%$ completed 36 months of follow-up during 2010-2012. The age distribution matched that of the general population, women were underrepresented $(54 \%$ vs $60 \%$ for census area). ${ }^{14}$

The intervention and control groups were evenly matched on the characteristics assessed (Table 1). All 148 participants offered a home visit for additional disability assessment accepted. Intraclass correlation coefficients by practice for NEADL scores, AM-PAC scores, WHOQOLBREF physical, psychological, and social scores, Geriatric Depression Scale, and hospitalization in the last year were all less than 0.003 (negligible); the value for the WHOQOLBREF environmental score was 0.002 (95\% CI, 0.001-0.003).

\section{Main and Secondary Outcomes}

Residential care placement was more common for patients in the intervention group than for those in the control group: 173 (8.4\%) compared with 115 (6.2\%) (hazard ratio $=1.32 ; 95 \% \mathrm{CI}$, 1.04-1.68; $P=.02)$. There was no difference between groups in the overall proportions of patients hospitalized, which ranged from $6 \%$ to $10 \%$ during the trial, or the rate of ambulatory care-sensitive hospitalization $(P=.88)$. The rate of hospitalizations was 0.15 to 0.25 hospitalizations per person-year overall, with no significant difference between the groups $(P=.68)$ (Figure 2).

There was no significant difference between groups in the change in functional status assessed from NEADL scores $(P=.13)$ (Table 2). The
Table 1. Baseline Patient Characteristics

\begin{tabular}{|c|c|c|c|c|c|}
\hline Characteristic & $\mathbf{N}^{a}$ & $\begin{array}{l}\text { Intervention } \\
\text { Mean (SD) } \\
\text { or No. (\%) }\end{array}$ & $\begin{array}{l}\text { Control } \\
\text { Mean (SD) } \\
\text { or No. (\%) }\end{array}$ & $\begin{array}{c}P \\
\text { Value }\end{array}$ & $\begin{array}{l}\text { Total } \\
\text { Mean (SD) } \\
\text { or No. (\%) }\end{array}$ \\
\hline \multicolumn{6}{|l|}{ Demographics } \\
\hline Age, mean (SD), y & 3,753 & $80.4(4.6)$ & $80.3(4.5)$ & .53 & $80.3(4.6)$ \\
\hline Sex, female, No. (\%) & 3,737 & $1,101(56)$ & $951(54)$ & .21 & $2,052(55)$ \\
\hline Married, No. (\%) & 3,711 & $1,038(53)$ & $945(54)$ & .66 & $1,983(53)$ \\
\hline Living alone, No. (\%) & 3,738 & $824(42)$ & $724(41)$ & .57 & $1,548(41)$ \\
\hline Education, No. (\%) & 3,598 & & & .64 & \\
\hline Primary school & & $270(14)$ & $251(15)$ & & $521(14)$ \\
\hline Secondary school & & $882(47)$ & $763(45)$ & & $1,645(46)$ \\
\hline Tertiary qualification & & 739 (39) & $693(41)$ & & $1,432(40)$ \\
\hline $\begin{array}{l}\text { Main lifetime occupa- } \\
\text { tion, No. (\%) }\end{array}$ & 3,706 & & & .97 & \\
\hline Professional & & $681(35)$ & $639(36)$ & & $1,320(36)$ \\
\hline Managerial/technical & & $935(48)$ & $793(45)$ & & $1,728(47)$ \\
\hline Clerical/laborers & & $332(17)$ & $326(19)$ & & $658(18)$ \\
\hline \multicolumn{6}{|l|}{ Clinical characteristics } \\
\hline $\begin{array}{l}\text { Total medications, } \\
\text { mean (SD) }\end{array}$ & 2,849 & $4.29(3.24)$ & $4.10(3.11)$ & .01 & $4.20(3.18)$ \\
\hline $\begin{array}{l}\text { Hospitalized in last } \\
12 \mathrm{mo} \text {, No. (\%) }\end{array}$ & 3,752 & $158(8)$ & $152(9)$ & .52 & $310(8)$ \\
\hline \multicolumn{6}{|l|}{ Diagnoses, No. $(\%)^{\mathrm{b}}$} \\
\hline Hypertension & 3,551 & $1,054(57)$ & $930(55)$ & .22 & $1,984(56)$ \\
\hline Myocardial infarction & 3,478 & $497(27)$ & $459(28)$ & .97 & $956(27)$ \\
\hline Cerebrovascular accident & 3,416 & $213(12)$ & $172(11)$ & .18 & $385(11)$ \\
\hline COPD & 3,441 & $126(7)$ & $124(7)$ & .65 & $250(7)$ \\
\hline Total No., mean (SD) ${ }^{c}$ & 3,524 & $0.46(0.66)$ & $0.46(0.62)$ & .72 & $0.45(0.64)$ \\
\hline Smoking, No. (\%) & 3,720 & & & .57 & \\
\hline Never smoker & & $905(46)$ & $804(46)$ & & $1,709(46)$ \\
\hline Past smoker & & $1,002(51)$ & $896(51)$ & & $1,898(51)$ \\
\hline Current smoker & & $54(3)$ & $59(3)$ & & $113(3)$ \\
\hline Fell in last 12 mo, No. (\%) & 3,721 & $622(32)$ & $576(33)$ & .47 & $1,198(32)$ \\
\hline \multicolumn{6}{|l|}{ Support services, No. (\%) } \\
\hline Any home help & 3,727 & $589(30)$ & $445(25)$ & .01 & $1,034(28)$ \\
\hline $\begin{array}{l}\text { Home help more than } \\
\text { once a week }\end{array}$ & 1,027 & $99(17)$ & $38(9)$ & $<.001$ & $137(13)$ \\
\hline Any personal care & 3,727 & $92(5)$ & $49(3)$ & .002 & $141(4)$ \\
\hline $\begin{array}{l}\text { Personal care more } \\
\text { than once a week }\end{array}$ & 139 & $83(92)$ & $46(94)$ & .72 & $129(93)$ \\
\hline $\begin{array}{l}\text { Cognition, AMTS score, } \\
\text { mean (SD) }\end{array}$ & 3,714 & $9.31(1.02)$ & $9.4(0.89)$ & $<.001$ & $9.35(0.96)$ \\
\hline $\begin{array}{l}\text { Depression, GDS-15 score } \\
\geq 5 \text {, No. (\%) }\end{array}$ & 3,726 & $184(9)$ & $158(9)$ & .66 & $342(9)$ \\
\hline \multicolumn{6}{|l|}{ Disabled subgroup } \\
\hline Sex, female, No. (\%) & 148 & $58(61)$ & $30(57)$ & .63 & $88(59)$ \\
\hline Age, mean (SD), y & 148 & $80.0(5.2)$ & $81.5(5.5)$ & .12 & $8.5(5.3)$ \\
\hline SPPB score, mean (SD) & 148 & $5.6(3.2)$ & $6.0(3.4)$ & .60 & $5.7(3.3)$ \\
\hline $\begin{array}{l}\text { Grip strength, mean (SD), } \\
\text { kg }\end{array}$ & 144 & $23.0(9.4)$ & $24.0(11.2)$ & .09 & $23.3(10.0)$ \\
\hline \multicolumn{6}{|c|}{$\begin{array}{l}\text { AMTS = Abbreviated Mental Test Score (higher score indicates better cognition; score of } \geq 7 \text { is considered normal); } \\
\text { COPD = chronic obstructive pulmonary disease; GDS- } 15=15 \text {-item Geriatric Depression Scale (higher score indicates } \\
\text { more depressive symptoms; score of } \geq 5 \text { is considered moderate depressive symptoms); SPPB = Short Physical Perfor- } \\
\text { mance Battery for physical function (measures physical performance, a combination of balance, gait speed, and chair } \\
\text { stands; scores range from } 0 \text { to } 12 ; \text { a higher score indicates better function). }\end{array}$} \\
\hline \multicolumn{6}{|c|}{$\begin{array}{l}\text { a Total with complete data included in analysis. } \\
\text { "Ascertained by the question "Have you ever been told by a doctor that you have or have had: high blood pressure, } \\
\text { asthma, diabetes, arthritis/rheumatism, epilepsy, Parkinson's disease, osteoporosis, heart attack or angina, stroke, } \\
\text { chronic bronchitis or emphysema, hip fracture, knee replacement, hip replacement, depression, or mental illness?" } \\
\text { " Excluding hypertension. }\end{array}$} \\
\hline
\end{tabular}


AM-PAC physical and movement domain showed a slower decline in the intervention group $(P=.03)$. On the WHOQOL-BREF, mean physical health scores fell on average by 2.9 points in the control group and 1.6 points in the intervention group $(P=.007)$ and mean psychological health scores fell by 2.4 and 1.1 points, respectively $(P=.005)$. Changes in the environmental and social domains of the WHOQOL-BREF did not differ between groups. There were trends toward less depression in the intervention group over time $(P=.06)$ and larger proportions of patients in the intervention group rating their primary care as "very good" or "excellent" in showing care and concern $(P=.06)$.
Intraclass correlation coefficients for the change in WHOQOL-BREF scores, NEADL scores, AM-PAC scores, hospitalization, and residential care placement were all less than .001 . The primary care practice attended was significantly related to change in WHOQOL-BREF physical scores $(P=.002)$, but not hospitalization $(P=.11)$.

Examining physical function in the prespecified subgroup with established disability, the intervention group had preservation of gait speed. This benefit was not, however, accompanied by benefit in terms of hospitalizations, quality of life, and AM-PAC scores in the subgroup (data not shown).

Figure 2. Ambulatory care-sensitive hospitalizations and overall hospitalizations, by study group.
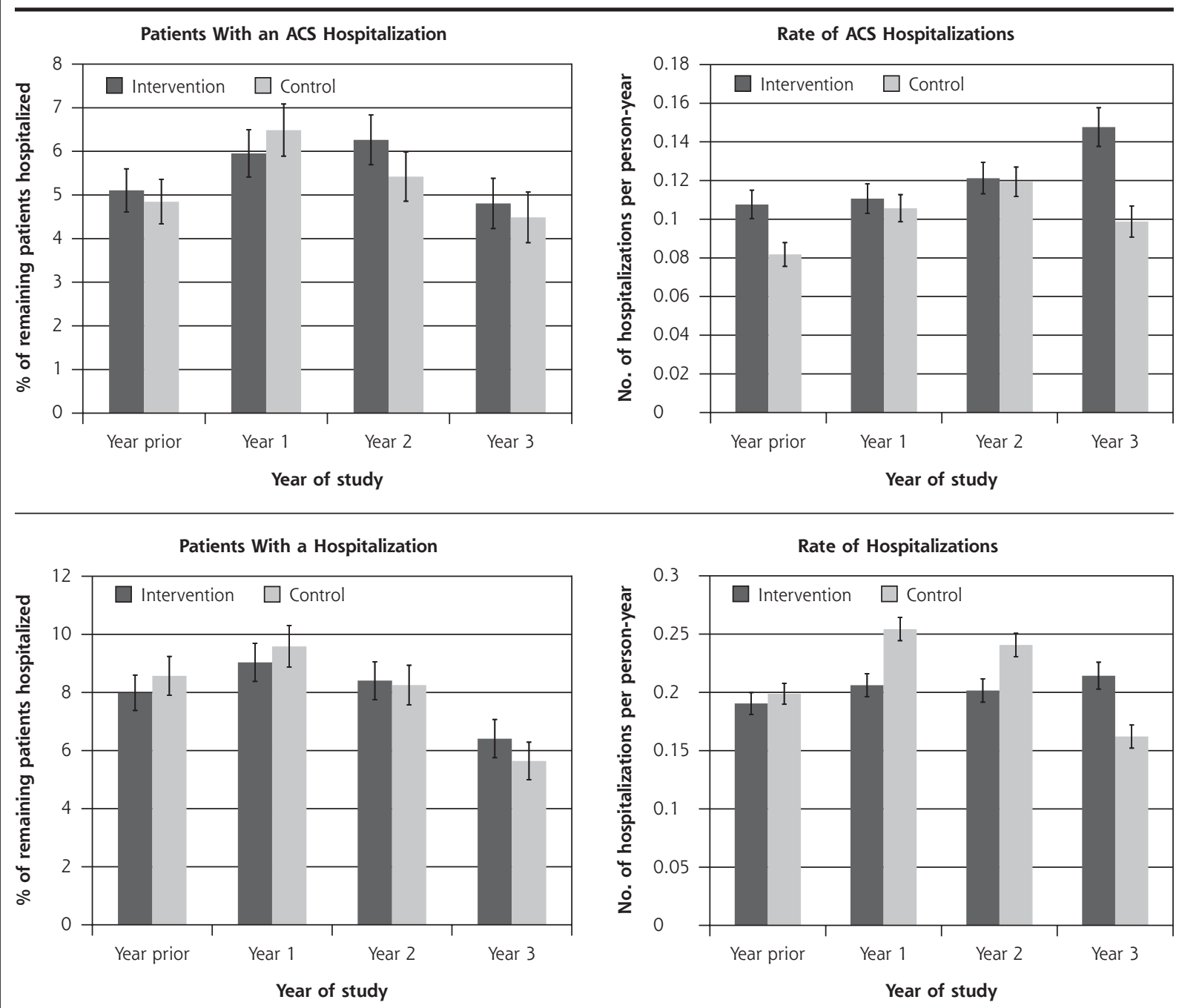

ACS = ambulatory care sensitive (hospitalizations resulting from diseases sensitive to good primary health care setting).

Notes: Hospitalizations were ascertained by matching encrypted National Health Identification (NHI) number, a unique identifier, with centrally held records of all hospital admissions from the New Zealand Ministry of Health ${ }^{27,28}$ at the end of the trial. International Classification of Diseases codes can be found and are used frequently in New Zealand. ${ }^{17}$ There was no significant difference between groups in the percentage of patients with an ACS hospitalization $(P=.82$ binomial mixed model regression, controlled for prior hospitalization and clustering) and rate of ACS hospitalizations ( $P=.88$ Poisson mixed model regression, controlled for number of prior hospitalizations and clustering), or in the percentage of patients with any hospitalization ( $P=.88$ binomial mixed model regression, controlled for prior hospitalization and clustering) and rate of any hospitalization ( $P=.68$ Poisson mixed model regression, controlled for number of prior hospitalizations and clustering). 
Table 2. Individual-Level Outcomes: 60 Practices and 3,893 Older Adults

\begin{tabular}{|c|c|c|c|c|c|}
\hline Outcome & $\mathbf{N}^{\mathrm{a}}$ & $\begin{array}{l}\text { Time } \\
\text { point, } \\
\text { mo }\end{array}$ & $\begin{array}{l}\text { Intervention } \\
\text { Mean (SD) } \\
\text { or No. (\%) }\end{array}$ & $\begin{array}{l}\text { Control } \\
\text { Mean (SD) } \\
\text { or No. (\%) }\end{array}$ & $\begin{array}{c}P \\
\text { Value }^{b}\end{array}$ \\
\hline \multirow[t]{3}{*}{ Function, NEADL score, mean (SD) } & 3,190 & 0 & $19.6(2.4)$ & $19.8(2.1)$ & .13 \\
\hline & & 18 & $19.4(2.8)$ & $19.4(2.7)$ & \\
\hline & & 36 & $19.4(3.0)$ & $19.3(3.0)$ & \\
\hline \multicolumn{6}{|l|}{ WHOQOL-BREF scores, mean (SD) } \\
\hline \multirow[t]{3}{*}{ Physical } & 3,741 & 0 & $70.4(16.4)$ & $71.4(16.3)$ & .007 \\
\hline & 3,410 & 18 & $70.3(16.8)$ & $70.5(17.0)$ & \\
\hline & 3,010 & 36 & $70.5(15.8)$ & $70.0(15.7)$ & \\
\hline \multirow[t]{3}{*}{ Psychological } & 3,732 & 0 & $73.0(11.8)$ & $73.7(12.0)$ & .005 \\
\hline & 3,407 & 18 & $72.5(12.5)$ & $72.9(12.4)$ & \\
\hline & 3,010 & 36 & $72.7(12.5)$ & $72.1(12.2)$ & \\
\hline \multirow[t]{3}{*}{ Social } & 3,729 & 0 & $79.0(13.4)$ & $79.6(13.3)$ & .13 \\
\hline & 3,401 & 18 & $79.6(13.0)$ & $79.3(13.3)$ & \\
\hline & 3,005 & 36 & $79.3(11.9)$ & $79.3(12.2)$ & \\
\hline \multirow[t]{3}{*}{ Environmentalc } & 3,742 & 0 & $80.2(11.2)$ & $80.3(11.4)$ & .20 \\
\hline & 3,411 & 18 & $80.7(11.5)$ & $80.2(11.8)$ & \\
\hline & 3,010 & 36 & $80.6(10.7)$ & $80.3(11.0)$ & \\
\hline \multicolumn{6}{|l|}{ AM-PAC scores, mean (SD) } \\
\hline \multirow[t]{3}{*}{ Physical and movement } & 2,118 & 0 & $64.7(6.7)$ & $65.1(6.9)$ & .03 \\
\hline & & 18 & $64.1(7.1)$ & $64.2(7.1)$ & \\
\hline & & 36 & $62.9(6.9)$ & $62.8(9.7)$ & \\
\hline \multirow[t]{3}{*}{ Personal care instrumental } & 2,117 & 0 & $60.5(8.6)$ & $60.8(8.9)$ & .42 \\
\hline & & 18 & $59.8(8.8)$ & $59.6(9.1)$ & \\
\hline & & 36 & $60.6(9.4)$ & $60.6(9.3)$ & \\
\hline \multirow[t]{3}{*}{ Depression, GDS-15 score, mean (SD) } & 3,187 & 0 & $1.8(1.8)$ & $1.7(1.9)$ & .053 \\
\hline & & 18 & $1.9(2.0)$ & $2.0(2.1)$ & \\
\hline & & 36 & $2.0(2.1)$ & $2.1(2.1)$ & \\
\hline \multicolumn{6}{|l|}{$\begin{array}{l}\text { Satisfaction with your last consultation with } \\
\text { the primary care physician, No. (\%) }\end{array}$} \\
\hline \multirow[t]{3}{*}{ "Involves you,"d very good/excellent } & 3,128 & 0 & $1,294(85.8)$ & $1,217(86.0)$ & .21 \\
\hline & & 18 & $1,317(82.6)$ & $1,182(78.2)$ & \\
\hline & & 36 & $1,225(76.2)$ & $1,126(74.1)$ & \\
\hline \multirow[t]{3}{*}{ "Time spent," } & 3,145 & 0 & $1,232(79.2)$ & 1,199 (81.4) & .11 \\
\hline & & 18 & $1,209(75.5)$ & $1,105(72.6)$ & \\
\hline & & 36 & $1,119(69.4)$ & $1,026(67.0)$ & \\
\hline \multirow[t]{3}{*}{ "Care and concern,,$"$ very good/excellent } & 3,137 & 0 & $1,350(85.9)$ & $1,262(85.7)$ & .16 \\
\hline & & 18 & $1,332(83.3)$ & $1,184(77.9)$ & \\
\hline & & 36 & $1,260(78.2)$ & $1,149(75.3)$ & Table 2 continues \\
\hline \multicolumn{6}{|c|}{$\begin{array}{l}\text { AM-PAC = Activity Measure for Post-Acute Care (measures functional ability, a higher score indicates better function); GDS-15 }=15 \text {-item Geriatric Depression Scale } \\
\text { (higher score indicates more depressive symptoms and a score of } \geq 5 \text { is considered moderate depressive symptoms); NEADL = Nottingham Extended Activities of Daily } \\
\text { Living Scale (score ranges from } 0 \text { to } 22 ; \text { higher score indicates greater independence); SPPB = Short Physical Performance Battery (measures physical performance, a } \\
\text { combination of balance, gait speed, and chair stands; scores range from } 0 \text { to } 12 ; \text { a higher score indicates better function); WHOQOL-BREF = abbreviated version of the } \\
\text { World Health Organization Quality of Life Scale (scores range from } 1 \text { to } 100 ; \text { a higher score means better QOL). }\end{array}$} \\
\hline \multicolumn{6}{|c|}{$\begin{array}{l}\text { a Total with complete data included in analysis. } \\
\text { b Result of generalized regression models with repeated measures adjusted for clustering by pr } \\
\text { "Domain of the WHOQOL-BREF (maximum score is 100; higher score indicates better quality o } \\
\text { d Ascertained by asking "[How satisfied are you with] how much the doctor involves you in dec } \\
\text { e Ascertained by asking "[How satisfied are you with] the amount of time your doctor spends } \\
\text { † Ascertained by asking "[How satisfied are you with] the doctor's care and concern for you?" }\end{array}$} \\
\hline
\end{tabular}

\section{Intervention Process Tracking}

The majority $(88 \%)$ of the intervention group received, completed, and returned the BRIGHT tool to practices. Figure 1 shows trigger and referral rates for the entire trial population.
We used Ministry of Health data to establish use of the geriatric assessment and rehabilitation services by all participants. Details of the initial assessment outcome were available for 1 center. In that center, 127 BRIGHT intervention patient referrals were 
Table 2. Individual-Level Outcomes: 60 Practices and 3,893 Older Adults (continued)

\begin{tabular}{|c|c|c|c|c|c|}
\hline Outcome & $\mathbf{N}^{\mathrm{a}}$ & $\begin{array}{l}\text { Time } \\
\text { point, } \\
\text { mo }\end{array}$ & $\begin{array}{l}\text { Intervention } \\
\text { Mean (SD) } \\
\text { or No. (\%) }\end{array}$ & $\begin{array}{l}\text { Control } \\
\text { Mean (SD) } \\
\text { or No. (\%) }\end{array}$ & $\begin{array}{c}P \\
\text { Value }^{b}\end{array}$ \\
\hline \multicolumn{6}{|l|}{ Support services, No. (\%) } \\
\hline \multirow[t]{3}{*}{ Any home help } & 3,727 & 0 & $589(30)$ & $445(25)$ & .80 \\
\hline & 3,406 & 18 & $538(30)$ & $426(26)$ & \\
\hline & 3,011 & 36 & $627(40)$ & $502(35)$ & \\
\hline \multirow[t]{3}{*}{ Home help more than once a week } & 1,025 & 0 & $99(17)$ & $38(9)$ & $<.01$ \\
\hline & 960 & 18 & $80(15)$ & $51(12)$ & \\
\hline & 1,128 & 36 & $85(14)$ & $54(11)$ & \\
\hline \multirow[t]{3}{*}{ Any personal care } & 3,727 & 0 & $92(5)$ & $49(3)$ & .23 \\
\hline & 3,405 & 18 & $102(6)$ & $79(5)$ & \\
\hline & 3,011 & 36 & $104(7)$ & $80(6)$ & \\
\hline \multirow[t]{3}{*}{ Personal care more than once a week } & 139 & 0 & $83(92)$ & $46(94)$ & $<.01$ \\
\hline & 177 & 18 & $89(89)$ & $70(91)$ & \\
\hline & 184 & 36 & $94(90)$ & $73(91)$ & \\
\hline \multicolumn{6}{|l|}{ Disabled subgroup } \\
\hline \multirow[t]{3}{*}{ SPPB score, mean (SD) } & 149 & 0 & $5.6(3.2)$ & $6.0(3.4)$ & .28 \\
\hline & 112 & 18 & $7.0(3.2)$ & $6.9(3.0)$ & \\
\hline & 78 & 36 & $7.1(3.0)$ & $8.3(2.2)$ & \\
\hline \multirow[t]{3}{*}{ Grip strength, mean (SD), kg } & 144 & 0 & $23.0(9.4)$ & $24.0(11.2)$ & .07 \\
\hline & 122 & 18 & $22.9(9.5)$ & $24.8(11.4)$ & \\
\hline & 89 & 36 & $23.2(8.9)$ & $24.5(11.5)$ & \\
\hline \multirow[t]{3}{*}{ 30-m walk distance, mean (SD), m } & 93 & 0 & $32.2(28.3)$ & $26.5(8.2)$ & .051 \\
\hline & 74 & 18 & $35.1(35.3)$ & $42.4(64.6)$ & \\
\hline & 60 & 36 & $33.6(17.5)$ & $27.1(6.4)$ & \\
\hline \multirow[t]{3}{*}{ 3-m gait speed, mean (SD), m/sec } & 138 & 0 & $5.8(5.1)$ & $4.7(2.6)$ & .04 \\
\hline & 123 & 18 & $5.0(3.3)$ & $5.2(4.1)$ & \\
\hline & 89 & 36 & $5.0(3.5)$ & $3.8(1.9)$ & \\
\hline \multicolumn{6}{|c|}{$\begin{array}{l}\text { AM-PAC = Activity Measure for Post-Acute Care (measures functional ability, a higher score indicates better function); GDS- } 15=15 \text {-item Geriatric Depression Scale } \\
\text { (higher score indicates more depressive symptoms and a score of } \geq 5 \text { is considered moderate depressive symptoms); NEADL }=\text { Nottingham Extended Activities of Dail) } \\
\text { Living Scale (score ranges from } 0 \text { to } 22 \text {; higher score indicates greater independence); SPPB = Short Physical Performance Battery (measures physical performance, a } \\
\text { combination of balance, gait speed, and chair stands; scores range from } 0 \text { to } 12 ; \text { a higher score indicates better function); WHOQOL-BREF = abbreviated version of th } \\
\text { World Health Organization Quality of Life Scale (scores range from } 1 \text { to } 100 ; \text { a higher score means better QOL). }\end{array}$} \\
\hline \multicolumn{6}{|l|}{ a Total with complete data included in analysis. } \\
\hline
\end{tabular}

made to the geriatric team between 2009 and end of 2011. Among these patients, 119 had an assessment, 2 went into care, 4 declined care, 1 could not be contacted, and 1 had no reason for nonassessment. Of those assessed, 85 (67\% of all referred from primary care) were considered to need no further action. Of the remainder, 13 (10\% of total) were referred for increased community services-10 (8\%) for home occupational therapy, physiotherapy, or the acute community response team for multidisciplinary assessment ${ }_{i}$ 2 to the district nursing service; and 4 to specialist services for pain or vertigo or to the primary care physician for review - and the remaining 5 were given advice about community social services.

There was no significant difference between groups in geriatric services received, including a variety of assessments (international residential assessment instrument [interRAI] Home Care Assessments, phys- iotherapist, gerontology nursing, and geriatric medical assessment) (Figure 3), emergency department use (Figure 4), and nongeriatric outpatient hospital use (data not shown). Self-reported use of home help and personal care did not differ between the groups over the 36 months of follow-up overall, but the intensity differed, with the control group receiving more intensive services. During the trial, all regional geriatric services were reformed to some degree, causing some disruption to the timing of patient assessment.

No adverse events were reported among study participants.

\section{DISCUSSION}

Our case-finding intervention was successful in identifying older adults in need, the first step in our 2-step process aiming to reduce disability, but identification 
Figure 3. Use of geriatric assessment and rehabilitation community services.

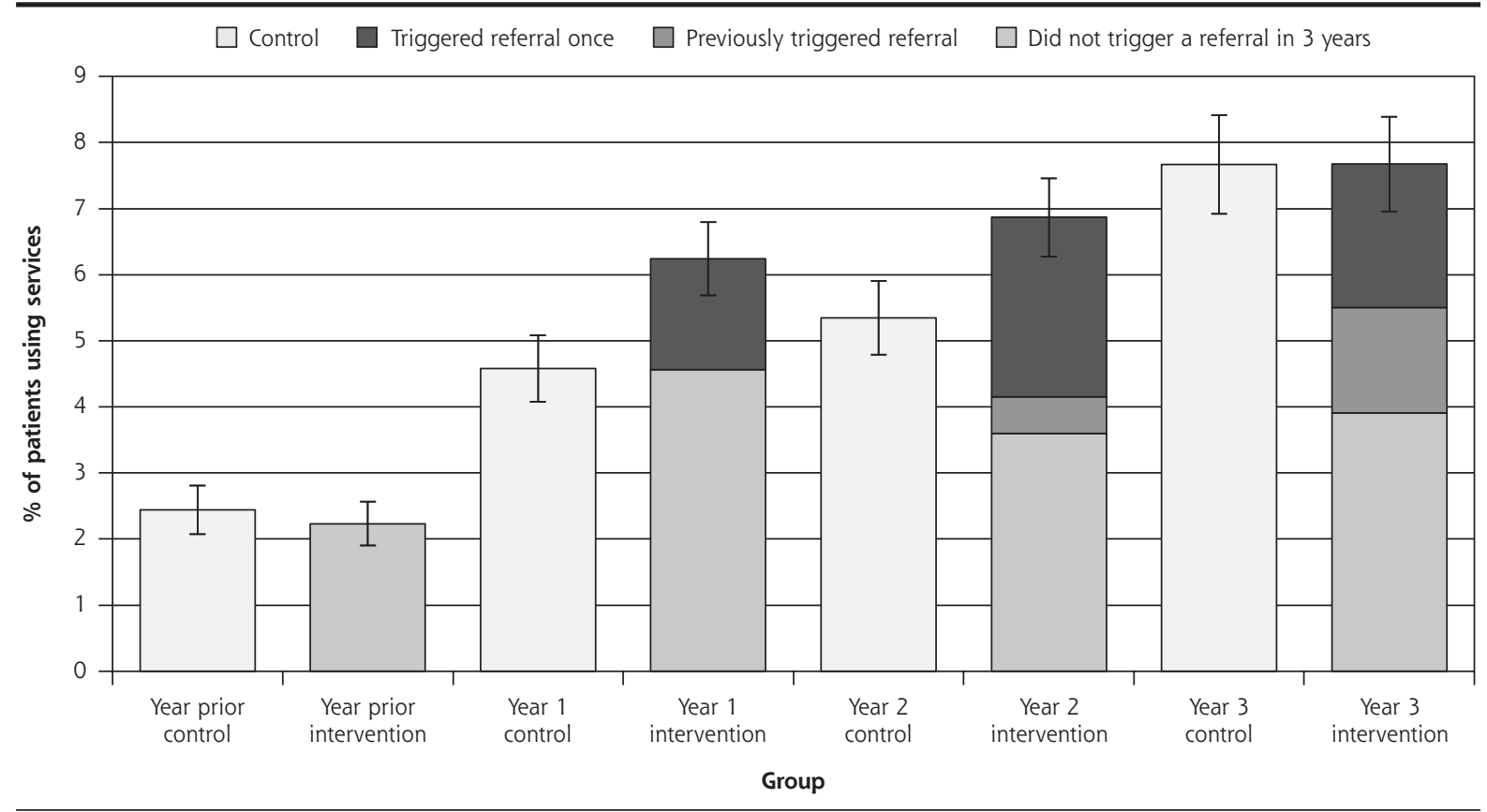

Notes: There was no significant difference between intervention and control groups over time in the percentages of patients who had a geriatric assessment and/or used rehabilitation community services during the trial $(P=.09)$. Figure shows all outpatient geriatric assessment and rehabilitation services used, including comprehensive assessment, physiotherapy, occupational therapy, social work, gerontology nursing, and case management by group. Shown for the intervention group are patients for whom Brief Risk Identification Geriatric Health Tool (BRIGHT) scores triggered referral once (darkest section of bar), had triggered previously (dark section of bar), and did not trigger during the 3 years (lighter section of intervention bars). Lightest bar is the control group.

\section{Figure 4. Use of emergency departments.}

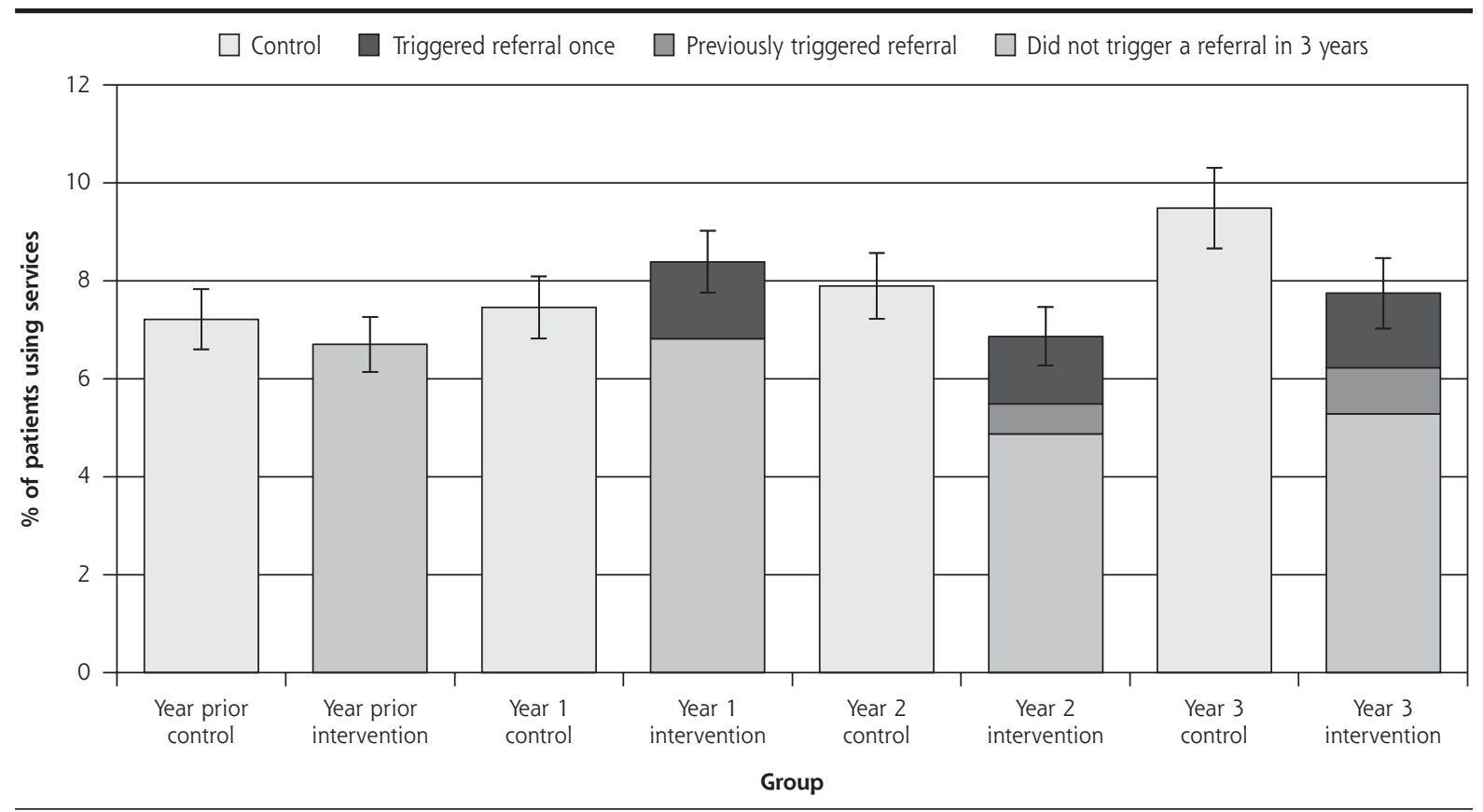

Notes: There was no significant difference between intervention and control groups over time in emergency department use during the trial $(P=.27)$. Shown for the intervention group are patients for whom Brief Risk Identification Geriatric Health Tool (BRIGHT) scores triggered referral once (darkest section of bar), had triggered previously (dark section of bar), and did not trigger during the 3 years (lighter section of intervention bars). Lightest bar is the control group. 
did not reduce use of acute hospital services, and use of residential care increased. It is possible that participants admitted to residential care benefitted. There was a small, significant benefit in terms of healthrelated quality of life and function as measured by the AM-PAC ${ }^{29}$; however, it may not be clinically relevant.

Either the second step of integrated geriatric health care was not effective (ie, more older adults were sent but outcomes did not improve), or control patients had adequate access to the same care, meaning there was no need for the screening. The observed increase in residential care supports the former, in that persons with unmet need were identified and placed in 24-hour care. Other trials have found that preventive strategies have increased residential care placement and hospitalization, ${ }^{2-4}$ suggesting that residential care may be underused in some contexts. Researchers and health planners in other systems considering screening to systematically identify those in need should carefully consider the entirety of the response. Identification without appropriate action may not lead to a desirable result.

Comparing our results with those of similar trials in which interventions were effective, there is a clear difference relative to the trial of Pathy et al ${ }_{1}^{10}$ which tested a successful 2-step process in Canada in which the second step was enhanced primary care. Our trial did not enhance the service response, and there was no change in rehabilitative or other service use, findings consistent with other research wherein comprehensive geriatric assessment resulted in recognizing need but not an increase in supports. ${ }^{21} \mathrm{New}$ Zealand has high residential care use, ${ }^{22}$ and potentially, institutionalization was the easiest response to unmet need. The Netherlands has also found more intensive, tailored, additional service models to be unsuccessful ${ }^{30}$ despite being well received. ${ }^{31}$ Both countries have integrated publicly funded accessible services for older people. Our control group also had access to these services and was engaged with primary care. It may not have been possible to improve on usual care by a systematic identification process alone.

Other interventions have improved outcomes for older people in the United States. ${ }^{32,33}$ Both Guided Care $^{32}$ and Geriatric Resources for Assessment and Care of Elders (GRACE) ${ }^{33}$ added expert nurses in the context of new multidisciplinary access for older people. The expert in these interventions was empowered to access all rehabilitative processes, ensuring delivery. The interventions clearly increased services and provided new expertise.

Our result may be relevant to other health systems wherein similar groups of reasonably well older people are cared for in integrated systems, such as the
US health maintenance organization population. In contrast, new trials of screening or case finding may be successful in other populations having poorly organized or less coordinated primary health care. In such systems, researchers should attempt to differentiate whether primary care itself is being created, or services and therapies are more effectively reaching an identifiable target group of older adults in need.

An ideal strategy for New Zealand, where publicly accessible multidisciplinary care is already available, may entail real integration of such care into primary care with a bolstered workforce to emphasize skills and knowledge to empower older adults, as well as expert medical assessment and knowledge of rehabilitation and multimorbidity management. Together with community-accessible activity areas and social integration, increased focus on age-friendly communities, not just within the health system, may be needed to reduce disability in older people. Further trials should compare substantially changed ways of working with older people with a true usual care group and carefully evaluate the changes in services and social integration.

The generalizability of our findings may be limited by the less than $50 \%$ response rate at the patient level and the high educational and occupational level of the enrolled patients. These factors may have led to underestimation of the effect of the intervention as it would be expected that more unmet need may be found in lower socioeconomic status groups and less engaged groups. This trial should be interpreted in the context of the New Zealand system.

In conclusion, our case-finding strategy was effective in increasing identification of people with disability, but there was little evidence of response from the health system apart from residential care placement (which may have been needed). Further research should trial enhancement of primary care in integrated systems.

To read or post commentaries in response to this article, see it online at http://www.annfammed.org/content/12/6/514.

Key words: population screening; older adults; disability; practicebased research; primary care; early medical intervention

Submitted January 21, 2014; submitted, revised, July 1, 2014; accepted July 9, 2014.

Funding support: The trial was funded by program grant 06-068 and program grant extension 09-068 from the Health Research Council of New Zealand. C.M. and S.A.M. had financial support for their research salary and T.N. had financial support for a PhD stipend from the Health Research Council of New Zealand, a government research funding source, for the submitted work.

Previous presentations: A presentation of similar content was made to the North American Primary Care Research Group Scientific Meeting in New Orleans, Louisiana, in December 2012, and at the General Practice Conference of New Zealand, in Auckland, New Zealand, September 2012. 
Disclaimer: The funders had no involvement in the study design, conduct, interpretation, manuscript preparation, or decision to publish. All researchers acted independently from the funder and had access to the data.

Acknowledgments: We acknowledge the willing participation of the practices and older adults. Thank you to Stuart Parker and Janet Blom for commenting on the manuscript before submission. Elizabeth Robinson completed the randomization schedule and informed C.M. of practice allocation. We acknowledge Sue Vernall and Sue Gifford for supporting the practices in the intervention and assisting in recruitment; Jenny Bush, Jenny Schrader, and Penny McPhail, who completed blinded assessments and recruitment; and Angela Robinson for supporting the project.

Supplementary materials: Available at http://www.AnnFamMed. org/content/12/6/514/suppl/DC1/

\section{References}

1. Beswick AD, Rees K, Dieppe $P$, et al. Complex interventions to improve physical function and maintain independent living in elderly people: a systematic review and meta-analysis. Lancet. 2008;371(9614):725-735

2. Lin JS, Whitlock EP, Eckstrom E, et al. Challenges in synthesizing and interpreting the evidence from a systematic review of multifactorial interventions to prevent functional decline in older adults. J Am Geriatr Soc. 2012;60(11):2157-2166.

3. Byles JE, Tavener M, O'Connell RL, et al. Randomised controlled trial of health assessments for older Australian veterans and war widows. Med J Aust. 2004;181(4):186-190.

4. Commonwealth Department of Health and Aged Care. The Australian Coordinated Care Trials: Final Technical National Evaluation Report of the First Round of Trials. Canberra, Australia: Commonwealth Department of Health and Aged Care; 2001.

5. Fletcher AE, Jones DA, Bulpitt CJ, Tulloch AJ. The MRC trial of assessment and management of older people in the community: objectives, design and interventions. BMC Health Serv Res. 2002;2(1):21.

6. Hajat S, Haines A, Bulpitt C, Fletcher A. Patterns and determinants of alcohol consumption in people aged 75 years and older: results from the MRC trial of assessment and management of older people in the community. Age Ageing. 2004;33(2):170-177.

7. Leichsenring K. Developing integrated health and social care services for older persons in Europe. Int J Integr Care. 2004;4:e10. https://www.ijic.org/index.php/ijic/article/view/107. Accessed Nov 22, 2013.

8. Douglass C. The development and evolution of geriatric assessment teams over the past 25 years: a cross-cultural comparison of the US and the UK. J Interprof Care. 2001;15(3):267-280.

9. Williams BC, Paik JL, Haley LL, Grammatico GM. Centralized care management support for "high utilizers" in primary care practices at an academic medical center. Care Manag J. 2014;15(1):26-33.

10. Pathy MS, Bayer A, Harding K, Dibble A. Randomised trial of case finding and surveillance of elderly people at home. Lancet. 1992; 340(8824):890-893.

11. Ploeg J, Brazil K, Hutchison B, et al. Effect of preventive primary care outreach on health related quality of life among older adults at risk of functional decline: randomised controlled trial. BMJ. 2010; 340:c1480.

12. Kerse N, Boyd M, McLean C, Koziol-McLain J, Robb G. The BRIGHT tool. Age Ageing. 2008;37(5):553-588.

13. Donner A, Birkett N, Buck C. Randomization by cluster. Sample size requirements and analysis. Am J Epidemiol. 1981;114(6):906-914.

14. McLean C, Kerse N, Moyes SA, Ng T, Lin S-YS, Peri K. Recruiting older people for research through general practice: the Brief Risk Identification Geriatric Health Tool trial [published online ahead of print July 29, 2013]. Austr J Ageing. doi:10.1111/ajag.12058.
15. Hodkinson HM. Evaluation of a mental test score for assessment of mental impairment in the elderly. Age Ageing. 1972;1(4):233-238.

16. Vinkers DJ, Gussekloo J, Stek ML, Westendorp RG, Van Der Mast RC. The 15-item Geriatric Depression Scale (GDS-15) detects changes in depressive symptoms after a major negative life event. The Leiden 85-plus Study. Int J Geriatr Psychiatry. 2004;19(1):80-84.

17. New Zealand Ministry of Health. Ngā Tapuae me ngā Raraunga: Methods and Data Sources. Wellington, New Zealand: Ministry of Health; 2010.

18. New Zealand Ministry of Health. Our Health, Our Future-Hauora pakari, koiora roa: The Health of New Zealanders. Wellington, New Zealand; Ministry of Health; 1999.

19. Essink-Bot ML, Krabbe PF, Bonsel GJ, Aaronson NK. An empirical comparison of four generic health status measures. The Nottingham Health Profile, the Medical Outcomes Study 36-item Short-Form Health Survey, the COOP/WONCA charts, and the EuroQol instrument. Med Care. 1997;35(5):522-537.

20. Jette AM, Haley SM, Tao W, et al. Prospective evaluation of the AM-PAC-CAT in outpatient rehabilitation settings. Phys Ther. 2007; 87(4):385-398.

21. Brown PM, Wilkinson-Meyers L, Parsons M, Weidenbohm K, McNeill R, Brandt T. Cost of prescribed and delivered health services resulting from a comprehensive geriatric assessment tool in New Zealand. Health Soc Care Community. 2009;17(5):514-521.

22. Broad J, Gott M, Kim H, Boyd M, Chen H, Connolly MJ. Where do people die: an international comparison of the use of hospitals and residential aged care at the end of life. Int Pub Health. 2013;58(2): 257-267.

23. Lin SY, Kerse N, McLean C, Moyes SA. Validation of quality of life and functional measures for older people for telephone administration. J Prim Health Care. 2010;2(1):35-42.

24. Guralnik JM, Ferrucci L, Pieper CF, et al. Lower extremity function and subsequent disability: consistency across studies, predictive models, and value of gait speed alone compared with the short physical performance battery. J Gerontol A Biol Sci Med Sci. 2000; 55(4):M221-M231.

25. interRAI. interRAI instruments: Home Care. interRAI website. http:// www.interrai-au.org/range.htm. Accessed Oct 25, 2005.

26. Campbell MK, Piaggio G, Elbourne DR, Altman DG; CONSORT Group. Consort 2010 statement: extension to cluster randomised trials. BMJ. 2012;345:e5661.

27. Kao S, Lai K-L, Lin H-C, Lee H-S, Wen H-C. WHOQOL-BREF as predictors of mortality: a two-year follow-up study at veteran homes. Qual Life Res. 2005;14(6):1443-1454.

28. Naumann VJ, Byrne GJ. WHOQOL-BREF as a measure of quality of life in older patients with depression. Int Psychogeriatr. 2004; 16(2):159-173.

29. Jette A, Haley S, Coster W, Ni P; Boston University Health and Disability Research Institute. Activity Measure for Post Acute Care (AM-PAC). Newburyport, MA: CREcare, LLC; 2007.

30. Metzelthin SF, van Rossum E, de Witte LP, et al. Effectiveness of interdisciplinary primary care approach to reduce disability in community dwelling frail older people: cluster randomised controlled trial. BMJ. 2013;347:f5264.

31. Metzelthin SF, Daniëls R, van Rossum E, et al. A nurse-led interdisciplinary primary care approach to prevent disability among community-dwelling frail older people: a large-scale process evaluation. Int J Nurs Stud. 2013;50(9):1184-1196.

32. Boult C, Reider L, Frey K, et al. Early effects of "Guided Care" on the quality of health care for multimorbid older persons: a clusterrandomized controlled trial. J Gerontol A Biol Sci Med Sci. 2008; 63(3):321-327.

33. Counsell SR, Callahan CM, Buttar AB, Clark DO, Frank KI. Geriatric Resources for Assessment and Care of Elders (GRACE): a new model of primary care for low-income seniors. J Am Geriatr Soc. 2006;54(7):1136-1141. 